ScIDice

\section{Prevalence of Lingual Arch Space Maintainer among Children between the Age Groups Of 6-10 Years - A Retrospective Study}

Research Article

Trinaina Somas Kandhan ${ }^{1}$, Ganesh Jeevanandan ${ }^{2 *}$, Arvina Rajasekar ${ }^{3}$

${ }^{1}$ Saveetha Dental College And Hospitals, Saveetha Institute Of Medical and Technical Sciences, Saveetha University, Chennai,600050, India.

${ }^{2}$ Reader, Department of Pedodontics, Saveetha Dental College and Hospitals, Saveetha Institute Of Medical And Technical Sciences, Saveetha University, Chennai, India.

${ }^{3}$ Senior Lecturer, Department of Periodontics, Saveetha Dental College and Hospitals, Saveetha Institute Of Medical And Technical Sciences, Saveetha University, Chennai, India.

Abstract

In 1887, Davenport described space loss resulting from premature loss of deciduous teeth. The causes for tooth loss can be deep dental caries, trauma or iatrogenic damage, and congenital absence. About $51 \%$ of the prematurely lost first deciduous molars and $70 \%$ of prematurely lost second deciduous molars cause loss of space and subsequent effects such as malposition or impaction of a permanent tooth in that quadrant, tipping of the first permanent molar, and crowding in the dental arch. Space maintenance in the developing dentition can prevent unnecessary loss of arch length. Various space maintainers have been used to cope with these problems. This study aims to assess the prevalence of Lingual Arch Space Maintainer among children between the age group of 6-10 years. A retrospective cross-sectional study was conducted using the patient records from the Department of Pedodontics, Saveetha Dental College, Chennai from June 2019-April 2020, and children who underwent space maintainer therapy were collected by Non-probability sampling. Data was collected and then subjected to statistical analysis. A total of 14 children were subjected to space management therapy using lingual arch space maintainer, out of this children of 9 years of age were predominantly exposed to lingual arch space maintainers, followed by 7 year old children. More males underwent lingual arch space maintainer therapy in comparison to females. The prevalence of lingual arch space maintainer among the mixed dentition phase in this study was higher when compared to prior studies that state that lingual arch space maintainer was not indicated among the specified age groups. Considering the previously stated limitations of the lingual arch space maintainer, extensive research regarding newer alternatives for space maintenance is to be carried out and awareness among dentists regarding the necessity for further such advancements is mandatory.

Keywords: Preventive Orthodontics; Space Maintainer; Lingual Arch Appliance; Mixed Dentition; Premature Loss.

\section{Introduction}

Premature loss of primary molars often causes undesirable drifting and loss of space [1]. In 1887, Davenport described space loss resulting from premature loss of deciduous teeth. The causes for tooth loss can be deep dental caries, trauma or iatrogenic damage, and congenital absence [2]. About $51 \%$ of the prematurely lost first deciduous molars and $70 \%$ of prematurely lost second deciduous molars cause loss of space and subsequent effects such as malposition or impaction of a permanent tooth in that quadrant, tipping of the first permanent molar, and crowding in the dental arch [3, 4]. Space maintenance in the developing dentition can prevent unnecessary loss of arch length. Various space maintainers have been used to cope with these problems. They are indicated for loss of at least one deciduous tooth, loss of arch perimeter, or a favorable prediction from the space analysis if it can be completed [5].

Space maintainers are fixed or removable appliances used to preserve arch length following the premature loss or elective extraction of a tooth/teeth. Retained primary teeth can also act as space maintainers [6]. The primary dentition plays a very important role in the child's growth and development, not only in terms of speech, chewing, appearance and the prevention of bad habits but also in the guidance and eruption of permanent teeth [7-9].

\footnotetext{
*Corresponding Author:

Ganesh Jeevanandan,

Reader, Department of Pedodontics, Saveetha Dental College And Hospitals, Saveetha Institute Of Medical And Technical Sciences, Saveetha University, Chennai, 600050, India. Tel: 9884293869

E-mail: ganesh.sdc@saveetha.com

Received: July 06, 2019

Accepted: July 30, 2019

Published: August 01, 2019

Citation: Trinaina Somas Kandhan, Ganesh Jeevanandan, Arvina Rajasekar. Prevalence of Lingual Arch Space Maintainer among Children between the Age Groups Of 6-10 Years - A Retrospective Study. Int J Dentistry Oral Sci. 2019;S8:02:005:21-25. doi: http://dx.doi.org/10.19070/2377-8075-SI02-08005
}

Copyright: Ganesh Jeevanandan ${ }^{\circ} 2019$. This is an open-access article distributed under the terms of the Creative Commons Attribution License, which permits unrestricted use, distribution and reproduction in any medium, provided the original author and source are credited. 
Exfoliation of primary teeth and eruption of permanent teeth is a normal physiological process. When this normal process is disrupted, due to factors like premature loss of primary teeth, proximal carious lesions etc, it may lead to mesial migration of teeth resulting in loss of the arch length which may manifest as malocclusion in permanent dentition in the form of crowding, impaction of permanent teeth, supraeruption of opposing teeth etc $[10,11]$. The best way to avoid these problems is to preserve the primary teeth in the arch till their normal time of exfoliation is attained. Hence it is rightly quoted that primary teeth serve as best space maintainers for permanent dentition $[12,13]$.

Space maintainer appliances are most commonly used to maintain the space created by early loss of a first or second primary molar while awaiting the eruption of its successor [14, 15]. Space management is an important responsibility of clinicians who are involved in monitoring the developing dentition, as the loss of arch length may lead to problems such as crowding, ectopic eruption, dental impaction, crossbite formation, and dental centre line discrepancies. The use of space maintainers may potentially obviate the need for later extractions and/or complex orthodontic treatment [16].

In preventive and interceptive orthodontics, the use of a mandibular fixed lingual appliance (FLA) is a commonly accepted procedure to maintain arch perimeter by preventing mesial tipping or drifting of the mandibular molars. Molar positions are stabilized against the mandibular incisors by the appliance, which also prevents the incisors from tipping lingually [17]. During the transition from the mixed to the permanent dentitions, developmental changes occur in the arch, including even the leeway space. Normally, the first molars move mesially into the leeway space, and arch length decreases. A lingual arch appliance on the mandibular molars is an effective device to maintain arch length by controlling mesial movement of the molars and to prevent the collapse of the mandibular incisors in a lingual direction [18].

Though the lingual arch space maintainer is widely used, it has many limitations such as the use of a lower fixed bilateral lingual arch appliance in the primary dentition is the potential for permanent incisors to erupt later behind the lingual arch wire [19, 20]. As well as the bacterial and food accumulation which leads to inflammation and pain. This study sheds light on the current scenario of Lingual Arch space maintainer as a treatment modality in the early mixed dentition phase by assessing the prevalence of lingual arch space maintainer among children between the age group of 6-10 years in Chennai.

\section{Materials and Methods}

\section{Study Design and Setting}

This pilot institution based retrospective study examined the records of 100 patients from June 2019-May 2020 undergoing treatment. The approval from the institutional ethics committee was obtained. The sample population included children who underwent lingual arch treatment by means of non probability sampling. Children with mental or physical disability unable to maintain oral hygiene and children with active lesions or systemic illnesses were excluded from the study.

\section{Data Collection}

Data was obtained from exclusive patient management software and was used to identify 14 patients out of 100 patients. Data relevant to the study such as Patients unique ID, Name, Age, Sex was recorded. Repeated patient records and incomplete records were excluded. Data was verified by an external reviewer.

\section{Statistical Analysis}

Data was recorded in Microsoft Excel 2016 (Microsoft Office 10) and later exported to the SPSS software for Windows (Version 20.0, SPSS Inc, IBM, Chicago Ill., USA) and subjected to statistical analysis. Chi square test was employed with significance level set at $\mathrm{p}<0.005$.

\section{Results and Discussion}

The final data consisted of 14 patients in total of Indian origin undergoing lingual arch space maintainer therapy, among the age group of $6-10$ years inclusive of both males and females. The mean age was $8.07+/-1.141$ years.

The age group associated with greatest prevalence of lingual arch space maintainers was 9 years $(35.7 \%, 5$ patients), followed by 7 and 8 years. (Table 1 ) The prevalence of space maintainers among the specified age group was depicted in a histogram. (Figure 1).

$71.4 \%$ patients out of the 6-10 year olds receiving lingual arch space maintainer therapy were males, thereby depicting a male predominance although the difference between the genders undergoing lingual arch therapy was not statistically significant $(\mathrm{p}>0.05)$. (Figure 2).

The data used in this retrospective study was based on the residents of Chennai. Currently, there are not many studies indicating and investigating the prevalence of lingual arch space maintainer as a treatment modality among the children with mixed dentition phase in Chennai. Since all of the data was included without a sorting process, no bias was expected in the selection of patients. The current study aims to shed light on the current scenario of lingual arch as a treatment modality in the early mixed dentition phase, which is the golden time for prevention of mesial tipping of erupting permanent teeth as described in prior studies.

Caries is the most prevalent dental disease both in the primary and the permanent dentition. In a study conducted by Kumar PM et.al, it was concluded that caries rate is high in permanent dentition than in primary dentition and more in children studying in Corporation schools than in Private schools [21]. The reason could be due to the fact that permanent teeth are exposed to a cariogenic diet from the time of eruption till the teeth are in situ. This reinforced the importance of curbing dental caries from childhood so as to ensure proper vitality and integrity of permanent dentition [22, 23].

Early losses of deciduous teeth have often been studied because of their relevance and association with occlusion abnormality, so that in the mixed phase, space maintainers are used to maintain the space corresponding to the permanent successor teeth. The loss of arch length resulting from this process can lead to the 
Table 1. This table depicts various age groups of children and the frequency and percentage prevalence of them undergoing lingual arch space maintainer therapy.

\begin{tabular}{|c|c|c|}
\hline AGE(YRS) & FREQUENCY & PERCENTAGE(\%) \\
\hline 6 & 1 & 7.1 \\
\hline 7 & 4 & 28.6 \\
\hline 8 & 3 & 21.4 \\
\hline 9 & 5 & 35.7 \\
\hline 10 & 1 & 7.1 \\
\hline
\end{tabular}

Figure 1. Histogram depicting the various age groups of children and the frequency prevalence of them undergoing lingual arch space maintainer therapy.

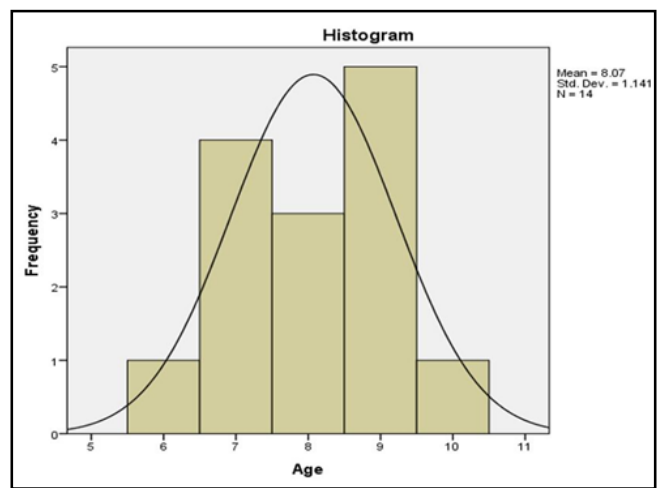

Histogram depicting the various age groups of children and the frequency prevalence of them undergoing lingual arch space maintainer therapy. $\mathrm{X}$ axis represents the various age groups of the children and the $\mathrm{Y}$ axis represents the frequency of undergoing treatment with lingual arch space maintainers. It is observed that the age group associated with greatest prevalence of lingual arch space maintainer was 9 years $(35.7 \%, 5$ patients).

Figure 2. Bar graph depicting the association between the gender and the different age groups undergoing treatment using lingual arch space maintainers.

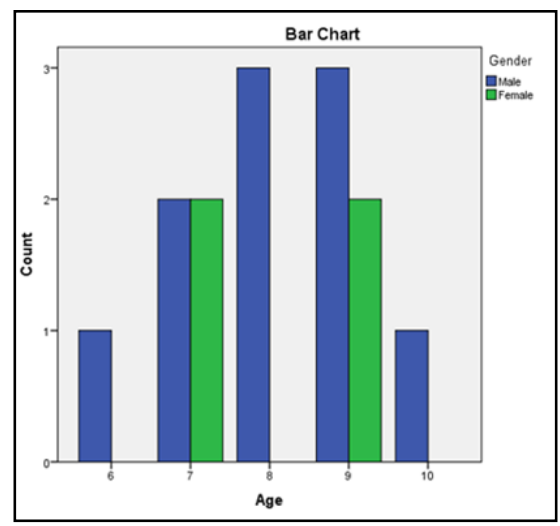

Bar graph depicting the association between the gender and the different age groups undergoing treatment using lingual arch space maintainers. $\mathrm{X}$ axis represents the different age groups and $\mathrm{Y}$ axis represents the number of male (blue) and female (green) patients undergoing treatment. There was an increase in male patients undergoing lingual arch space maintainer therapy, but this was not statistically significant. (Pearson Chi-square test, $\mathrm{p}=0.522 ; \mathrm{p}<0.05$; statistically insignificant)

development of several malocclusions in the permanent dentition [24]. The loss of a deciduous tooth is considered to be early or premature when it occurs at least one year before its normal exfoliation or after radiographic evidence that the permanent successor is still short of nolarstage, that is, with coronary formation and root formation not yet started. Several studies have been published regarding the premature loss of deciduous teeth $[25,26]$.

However, according to a study by Odom et.al, there is a great diversity of opinions about the clinical consequences of premature loss of deciduous teeth, especially regarding the need to use space maintainers [27].
A fixed lingual arch on the mandibular molars is commonly used as a holding device to maintain mandibular arch length and to prevent mesial migration of the mandibular first molars.In preventive and interceptive orthodontics, the use of a mandibular fixed lingual arch is a commonly accepted procedure $[28,29]$. It has been used primarily to maintain arch length by controlling the anterior movement of the molars and preventing the collapse of the mandibular incisors in a lingual direction. The effect, if any, the mandibular fixed lingual arch exercises on vertical control of the mandibular molars has not been adequately investigated [30].

Rebellato et al, found that the incisors extruded more than the molars [31]. However, Singer et.al, observed that the molar extru- 
sion was greater than that of the incisors [32]. The mandibular fixed lingual arch, as expected, also controlled the mesial movement of the molars and lingual tipping of the incisors. Therefore as the studies conducted by Mershon JV et al., proved the use of a mandibular fixed lingual arch as efficient in preserving arch length [33].

Based on the findings by Brennan et al., it is apparent that the lingual arch appliance placed in the period of early transitional dentition will restrict the mesial migration and use of the leeway space by the molars; therefore, a cusp-to-cusp molar relationship may not self-correct [34]. However, in patients with marginal crowding, a fixed lingual arch is an effective way to control space utilization in the mandibular arch.

From analysing previously conducted studies it was noted that the lingual arch is an effective appliance for maintaining space during the eruption of the permanent teeth, preserving molar anchorage, preventing arch length decrease, obtaining in some patients an arch length increase, and preventing the molars from tipping and the mandibular incisors from tipping lingually [35]. These effects could also resolve marginal crowding by controlling space use in the mandibular arch [36].

This study shows a male predominance towards space management therapy using lingual arch space maintainer which may be due to the predilection of males towards dental caries and dental trauma as well as established by previous literature [37, 38]. This may also be due to the small and limited sample size which thereby sheds light on the requirement for further studies so as to thoroughly analyze the prediction and prevalence of lingual arch therapy.

There is a predominance of children undergoing lingual arch therapy among the age group of 9 years in this study, which may be due to the eruption status in that age thereby cycling back to the fact that lingual arch space maintainers provided during the period of early transitional dentition will restrict the mesial migration and use of the leeway space by the molars, thereby preventing crowding or compromisation of arch space and perimeter.

In spite of all the studies contributing to the notion that lingual arch space maintainers are a gold standard for space management therapy, Few authors have reported disadvantages of the use of a lingual arch as a space maintainer, including possibility of extrusion of antagonist teeth, when considering the space left by the extracted tooth; non-reestablishment of the masticatory function; and previous history of sensibility to metallic materials.Despite these negative factors, the literature has recommended its use by demonstrating countless advantages that overcome all disadvantages.

\section{Acknowledgement and Declarations}

The authors of this study would like to express their gratitude towards everyone who facilitated and enabled us to carry out this study successfully.

\section{Conclusion}

Within the limitations of this institution based retrospective study, it is observed that lingual arch space maintainers are preferred among children of 9 years of age $(35.7 \%)$. This leads to the conclusion that the Nance lingual arch helps preserve the leeway space, which is of crucial importance in the transitional period of dentition among children. Its use as a space maintainer was long-term effective, and the small degree of relapse observed is normally expected during the process of occlusion maturation, thereby reinforcing the efficacy of this appliance.

Further studies are to be conducted to eliminate the minor disadvantages and further awareness is to be imparted among dentists so as to aid in better treatment planning protocol in patients so as to ensure proper treatment that ensures the desired results among children.

\section{References}

[1]. Laing E, Ashley P, Naini FB, Gill DS. Space maintenance. Int J Paediatr Dent. 2009 May;19(3):155-62.

[2]. Setia V, Pandit IK, Srivastava N, Gugnani N, Sekhon HK. Space maintainers in dentistry: past to present. J ClinDiagn Res. 2013 Oct;7(10):2402-5. Pubmed PMID: 24298544.

[3]. Green J. Mind the gap: Overview of space maintaining appliances. Dental Nursing. 2015 Jan 2;11(1):24-7.

[4]. Gray S, Stacknik S, Farella M. Space maintenance: An overview for clinicians. NZ Dent. J. 2016:76-80.

[5]. Terlaje RD, Donly KJ. Treatment planning for space maintenance in the primary and mixed dentition. ASDC J Dent Child. 2001 MarApr;68(2):109-14, 80.Pubmed PMID: 11475685.

[6]. Martins-Júnior PA, Ramos-Jorge ML, de Paiva SM, Pereira LJ, Marques LS. Premature deciduous tooth loss and orthodontic treatment need: a 6-year prospective study. J Public Health. 2017 Apr 1;25(2):173-9.

[7]. Goldenberg L. A retrospective cohort study of fixed space maintainers and a survey of their use by pediatric dentists and orthodontists [Internet]. University of Toronto (Canada); 2012. Available from: https://pdfs.semanticscholar.org/c496/a8637c41484a8f7ab948a6d34dad3f635a34.pdf

[8]. Lakshmanan L, Mani G, Jeevanandan G, Ravindran V, Ganapathi SE. Assessing the quality of root canal filling and instrumentation time using kedo$s$ files, reciprocating files and k-files. Braz Dent J. 2020 Jan 31;23(1):7.

[9]. Govindaraju L, Jeevanandan G, Subramanian E. Clinical Evaluation of Quality of Obturation and Instrumentation Time using Two Modified Rotary File Systems with Manual Instrumentation in Primary Teeth. J ClinDiagn Res. 2017 Sep;11(9):ZC55-ZC58.Pubmed PMID: 29207834.

[10]. Panchal V, Jeevanandan G, Subramanian E. Comparison of instrumentation time and obturation quality between hand K-file, H-files, and rotary Kedo$S$ in root canal treatment of primary teeth: A randomized controlled trial. J Indian SocPedodPrev Dent. 2019 Jan-Mar;37(1):75-79.Pubmed PMID: 30804311.

[11]. Ravikumar D, Jeevanandan G, Subramanian EM. Evaluation of knowledge among general dentists in treatment of traumatic injuries in primary teeth: A cross-sectional questionnaire study. Eur J Dent. 2017 Apr;11(2):232-7.

[12]. Jeevanandan G, Govindaraju L. Clinical comparison of Kedo-S paediatric rotary files vs manual instrumentation for root canal preparation in primary molars: a double blinded randomised clinical trial. Eur Arch Paediatr Dent. 2018 Aug;19(4):273-278.Pubmed PMID: 30003514.

[13]. Govindaraju L, Jeevanandan G, Subramanian EM. Knowledge and practice of rotary instrumentation in primary teeth among Indian dentists: a questionnaire survey. J Int OralHealth. 2017 Mar 1;9(2):45.

[14]. Govindaraju L, Jeevanandan G, Subramanian EMG. Comparison of quality of obturation and instrumentation time using hand files and two rotary file systems in primary molars: A single-blinded randomized controlled trial. Eur J Dent. 2017 Jul-Sep;11(3):376-379.Pubmed PMID: 28932150.

[15]. Jeevanandan G. Kedo-S Paediatric Rotary Files for Root Canal Preparation in Primary Teeth - Case Report. J ClinDiagn Res. 2017 Mar;11(3):ZR03ZR05.Pubmed PMID: 28511532.

[16]. Proffit WR, Fields Jr HW, Sarver DM. Contemporary orthodontics. Elsevier Health Sciences; 2006 Dec 8:768.

[17]. Baroni C, Franchini A, Rimondini L. Survival of different types of space maintainers. Pediatr Dent. 1994 Sep-Oct;16(5):360-1.Pubmed PMID: 7831141.

[18]. Almeida RR, Oltramari-Navarro PV, Almeida MR, Conti AC, Navarro Rde L, Pacenko MR. The nance lingual arch: an auxiliary device in solving 
lower anterior crowding. Braz Dent J. 2011;22(4):329-33.Pubmed PMID: 21861034.

[19]. Viglianisi A. Effects of lingual arch used as space maintainer on mandibular arch dimension: a systematic review. Am J OrthodDentofacialOrthop. 2010 Oct;138(4):382.e1-382.e4.Pubmed PMID: 20889031.

[20]. Nair M, Jeevanandan G, Vignesh R, Subramanian EM. Comparative evaluation of post-operative pain after pulpectomy with $\mathrm{k}$-files, kedo-s files and mtwo files in deciduous molars-a randomized clinical trial. Braz. Dent. Sci. 2018 Oct 24;21(4):411-7.

[21]. Mahesh Kumar P, Joseph T, Varma RB, Jayanthi M. Oral health status of 5 years and 12 years school going children in Chennai city--an epidemiological study. J Indian SocPedodPrev Dent. 2005 Mar;23(1):17-22.Pubmed PMID: 15858301.

[22]. Ramakrishnan M, Bhurki M. Fluoride, Fluoridated Toothpaste Efficacy And Its Safety In Children-Review. International Journal of Pharmaceutical Research. 2018 Oct 1;10(04):109-4.

[23]. Subramanyam D, Gurunathan D, Gaayathri R, Vishnu Priya V. Comparative evaluation of salivary malondialdehyde levels as a marker of lipid peroxidation in early childhood caries. Eur J Dent. 2018 Jan-Mar;12(1):67-70. Pubmed PMID: 29657527.

[24]. Moses J, Rangeeth BN, Gurunathan D. Prevalence of dental caries, socioeconomic status and treatment needs among 5 to 15 year old school going children of Chidambaram. J ClinDiagn Res. 2011 Feb;5(1):146-51.

[25]. Gurunathan D, Shanmugaavel AK. Dental neglect among children in Chennai. J Indian SocPedodPrev Dent. 2016 Oct 1;34(4):364-9.

[26]. Govindaraju L, Gurunathan D. Effectiveness of Chewable Tooth Brush in Children-A Prospective Clinical Study. J ClinDiagn Res. 2017 Mar;11(3):ZC31-ZC34.Pubmed PMID: 28511505.

[27]. Odom WM. Mixed dentition treatment with cervical traction and lower lingual arch. Angle Orthod. 1983 Oct;53(4):329-42.Pubmed PMID: 6580833 .
[28]. Kinzinger G, Fritz U, Diedrich P. Combined therapy with pendulum and lingual arch appliances in the early mixed dentition. J OrofacOrthop. 2003 May;64(3):201-13.Pubmed PMID: 12835892.

[29]. Miotti F. The passive lingual arch in first bicuspid extraction. Angle Orthod. 1984 Apr;54(2):163-75.Pubmed PMID: 6588772.

[30]. Villalobos FJ, Sinha PK, Nanda RS. Longitudinal assessment of vertical and sagittal control in the mandibular arch by the mandibular fixed lingual arch. Am J OrthodDentofacialOrthop. 2000 Oct;118(4):366-70.Pubmed PMID: 11029729.

[31]. Rebellato J, Lindauer SJ, Rubenstein LK, Isaacson RJ, Davidovitch M, Vroom K. Lower arch perimeter preservation using the lingual arch. Am J OrthodDentofacialOrthop. 1997 Oct;112(4):449-56.Pubmed PMID: 9345158.

[32]. Singer J. The effect of the passive lingual archwire on the lower denture. Angle Orthod. 1974 Apr;44(2):146-55.Pubmed PMID: 4524471.

[33]. Mershon JV. The removable lingual arch as an appliance for the treatment of malocclusion of the teeth. Int J Orthod. 1918 Nov 1;4(11):578-87.

[34]. Brennan MM, Gianelly AA. The use of the lingual arch in the mixed dentition to resolve incisor crowding. Am J OrthodDentofacialOrthop. 2000 Jan;117(1):81-5.Pubmed PMID: 10629524.

[35]. Christabel SL, Gurunathan D. Prevalence of type of frenal attachment and morphology of frenum in children, Chennai, Tamil Nadu. World J Dent. 2015 Oct;6(4):203-7.

[36]. Gianelly AA. Leeway space and the resolution of crowding in the mixed dentition. SeminOrthod. 1995 Sep;1(3):188-94.Pubmed PMID: 9002915.

[37]. Packiri S, Gurunathan D, Selvarasu K. Management of Paediatric Oral Ranula: A Systematic Review. J ClinDiagn Res. 2017 Sep;11(9):ZE06-ZE09. Pubmed PMID: 29207849.

[38]. Somasundaram S, Ravi K, Rajapandian K, Gurunathan D. Fluoride Content of Bottled Drinking Water in Chennai, Tamilnadu. J ClinDiagn Res. 2015 Oct;9(10):ZC32-4.Pubmed PMID: 26557612. 